\title{
Research on the Low Carbon Packaging of Food
}

\author{
Yanqi Liu \\ North China University of Water Resources and Electric Power \\ Zhengzhou, Henan, China 450045
}

\begin{abstract}
Now the food safety issue had become the subject relating people's livelihood, and in which the food packaging issue become more and more important, and had got much attentions. This paper was to research and analysis of the problems of food packaging at present stage, and investigated from the direction of low carbon environment-harmonious food packaging design. Then this study put forwarder several design ideas, such as: integrated design, simple design, packaging technology and material selection, etc.
\end{abstract}

Keywords-packaging of food; low carbon; environmentharmonious; research analysis

\section{INTRODUCTION}

In today's society, food safety issue had caused extensive concern of government and society. Food packaging was the vital part of food industry, as it could guarantee the stability of food quality, and prevent the damage in transporting. And after the use-up of these food, the food packaging had lost its value, would cause a certain burden to garbage collection. So, the developing mode of food packaging shall be based on the low pollution and low consumption. In the future, the food packaging need to realize the combination of low carbon environmental-harmonious and visual aesthetic. These not only could keep the food packaging beautiful, but also protect the environment. In the food production chain, the food packaging played a very important role.

\section{ThE PROBLEM ANALYSIS OF FoOd PACKAGING}

As is known to all, cloth, food, staying and travel was throughout the entire contents of the people's daily life, it meant that the food played an unusual role in our daily life. And the food industry was a very old production industry, and its production was accompanied with certain pollution problem. With the increasing of people's living standard, people were pursuing more and more high requirement of the quality of life. The economy were promoted to be low carbon and environment-harmonious, of which was leading the direction of food packing. And the design requirements of food packaging was to enable most consumers understand the information related product, and distinguish between food brand, companies and the propaganda image. At present, there were a lot of problems of packaging design in our country. As the packaging design was not reasonable, it lead to the waste of resources, and increased the burden of consumers, and also caused certain pollution to the environment, affected the health of human beings. And most of the food packaging just pursued its appearance, with complex design and more packing material and loose structure, while, ignored the low carbon standard for production pack material.

Nowadays, the most typical cases were the packaging of medicine, wine and cigarette. These excessive packaging not only wasted packing material, polluted the environment, but also caused consumers felt been cheated after purchased these products. And a lot of food packaging materials itself had a certain chemical composition and toxic substances. This cause poisoning, and made consumer in a danger condition. a lot of consumers different degrees of damage. A lot of packaging materials were applied on the packaging, such as oiling, waxing. Other packaging material was polystyrene, which could bring a good visual effect, but had threatened people's health. A lot of poisonous packaging materials was disposable. If it cannot be dealt well with or abandon it, it could cause serious pollution to the environment, and food packaging materials also existed some problems in design for safe usage. Now, most of the food packaging material could be plastic, paper, glass, etc. Detailed information was shown below: "Table I"

TABLE I. DETAILED INFORMATION OF THE FOOD PACKAGING MATERIAL

\begin{tabular}{|c|c|c|c|c|}
\hline $\begin{array}{c}\text { Food } \\
\text { Packaging } \\
\text { Material }\end{array}$ & Specification & Packaging Purpose & Advantage & Disadvantage \\
\hline Plastic & $\begin{array}{l}\text { The most widely used; security was the } \\
\text { most difficult to trace }\end{array}$ & $\begin{array}{l}\text { Edible oil, yogurt cups, packaged beverages, } \\
\text { carbonated drink, tea drink juice, mineral water }\end{array}$ & $\begin{array}{l}\text { Good Visibility and Low } \\
\text { cost }\end{array}$ & Food pollution, \\
\hline Metal & $\begin{array}{l}\text { Chemical Stability, Can inner coating } \\
\text { was the main issue. }\end{array}$ & Beer, carbonated drinks, non-carbonated drinks & $\begin{array}{l}\text { Processing Technology } \\
\text { Mature. }\end{array}$ & $\begin{array}{l}\text { Waste resources, } \\
\text { low security }\end{array}$ \\
\hline Paper & $\begin{array}{l}\text { Long history for food packaging, higher } \\
\text { technological requirements }\end{array}$ & Milk box, milk bags, fresh juice & High security & $\begin{array}{l}\text { Poor visibility, } \\
\text { high cost, difficult } \\
\text { to recycle }\end{array}$ \\
\hline Glass & $\begin{array}{l}\text { Most security, not convenient to } \\
\text { transport, the cap and cork were the } \\
\text { main issue }\end{array}$ & Beer, Canned food & $\begin{array}{l}\text { High visibility, high } \\
\text { security }\end{array}$ & breakable \\
\hline
\end{tabular}




\section{ANALYSIS STUDY OF LOW-CARBON FOOD PACKAGING}

The rapid development of industry has brought serious environmental problems, and food packaging had a very big impact on food safety issues.

\section{A. Analysis from the Packaging Materials}

1) Edible Packaging Materials: In recent years, some edible food packaging materials were applied more and more widely. Wafer became the edible food packing materials for packing candy etc, and corn baking packed ice cream, etc. There were a lot of plastic wrap of edible materials, these edible packaging film was made of biological macromolecules such as protein and sugar. The plastic wrap could be interacted into a kind of emulsion through the intermolecular. After certain processing of drying technology, the solvent inside evaporated, then eventually formed a transparent three-dimensional structure film. The film was with a good specification of waterproof and breathable performance, so it was widely applied in the preservation of vegetables and fruits.

2) Repeatability of Packaging Materials: The current situation, most of the packaging material could be reused, some alcohol, soy sauce and other daily items were packed in bottles, which could be reused. There were many drinks and bottle contained a lot of polyester which also could be repeated used. These could be repeated use of packaging, not only reduced the production cost of packaging material, but also improved the utilization efficiency of these packaging materials.

3) Degradability of Packaging Materials: Packaging materials were developed with the development of science and technology, many modern biodegradable packaging materials were degradable. These not only could realize the product packaging, but also could be degraded through biological photosynthesis into nontoxic substances after the usage. At present, there were a lot of food packing material met our requirement for environment protection and prevented oxygen to come to food interior and achieved the goal of keeping fresh. So, polyethylene plastic film used now would be replaced by a lot of new materials in the future, these new materials followed the state advocated development of low-carbon economy, would be used as the main material of food packaging design in the future.

\section{B. Analyzing from the Perspective of Packing Design}

The above study had analyzed the low carbon of packaging material, from the perspective of packaging design. For food packaging design, if company wanted to have a good effect, there were two factors must be considered, first was the innovative packaging design, which fully considered the visual perception of consumer, and consumers had a feeling of new and fresh. Second was packaging design should obey the requirement of low carbon environmental protection, a scientific design could fully reflect the quality of products, also could reduce the use of packaging materials, and conveyed to the consumer the brand characteristics of an enterprise. This made the products of enterprises be successful in the fierce market competition, and brought huge economic benefits for the enterprise.

To sum up, on food packaging design, our manufacturers should have the concept of low carbon environmental protection, and used some of the low carbon environmental protection material for packaging. This not only could improve the efficiency recycling of packaging materials, but also reduced the cost of enterprise and carbon emissions, and protected our ecological environment.

\section{CONCRETE DESIGN METHOd ANALYSIS OF FOOD LOW CARBON PACKAGING}

In general, what we told the food packaging design refers to the process of people using the words, picture and some other design method to convey basic information of the food. But, nowadays, many food enterprises did not accurately set the social status of their products, and not reasonable at packaging design. This unreasonable food packing cannot convey the basic information of the enterprise products to customers. And the design was not beautiful, and somehow it was rough, and some material were also in low quality. These factors would have the significant impact on company's food packing design. With the deepening of the low carbon and environment harmonious concept being popularizing, the innovative design method of low carbon environment protection became very important.

\section{A. Simple Method}

Simple method was widely used in the food packaging design, as the purpose of the simple method is to maximally decrease of the packaging material, through the expression elements and color packaging material. So this could had the artistic effect that complex and profound design could not do Most people thought the simple design was simply contracted. The fact was not like that, simple design method not only keeping people's life taste, but also promising the fashion, healthy, reasonable consumption concept. It give a person the sense with simple and fashionable. Simple method was a very practical design methods, which obeyed the advocated national low carbon economy requirement for food packaging. The purpose of using this design method was to avoid unnecessary waste of material and resources, and improve the repeated usage of packing materials, and then reduce the design cost of packaging materials and environmental protection. The cost and waste of resources, improve the repeated use of packaging materials, reduce the design cost of packaging materials, environmental protection. Simple design method not only could improve the economic efficiency of enterprises, but also could reflect the cultural values of an enterprise. 


\section{B. Synthesis Method}

In the design of food packaging, there was another method called synthesis. Literally, we could know that this was a comprehensive and integrated design method. This design method could be accepted by most consumers, at the same time, it also reflected in many aspects of the product. From product design to production, every step had the synthesis method. The emergence of this kind of design method was created in order to ensure that products meet the requirement of most consumers. The food packaging design was a comprehensive field, which combined the packaging materials, packaging technology, process design, food science, etc. So, the packaging design need to combined with many fields, and integrated a number of factors for innovative design. Integrated design method not only need to consider most consumers requirement, but also need to consider consumers occupation, desire and shopping sites. This could guarantee our food packaging be accepted by consumers, and improve the quality of life of consumers.

\section{Material Method}

For the success or failure of a packaging design, the key reason was to see the quality of the selected packaging materials, and it also would cause certain influence to the whole market. An environmental harmonious materials packaging design would stimulate consumption. Therefore, the food packaging materials was very important, the life cycle of a material could cause certain influence on the ecological environment. From the view of environmental protection, it need to be sure to choose low carbon environment protection material on food packaging design, and make the concept of low carbon environment protection throughout the packaging material in the whole process of design and usage, and fully realized the low carbonation of food packaging. At present, we had found and investigated a lot of low carbon materials, such as: light-pollution prevention packing material, nanometer packing material, special functional packaging material, edible packaging material, degerming packaging material, controlled biodegradable packaging material, water soluble packaging material, etc. So, food enterprises could choose the suitable low carbon packaging material based on nature of their products. This not only obeyed the national requirement for low carbon packaging, but also protected our ecological environment.

\section{Process Method}

In food packaging design, there was a kind of design named packaging process method. Because the packing process had important implications for food packaging, which related to the quality and effect of food packaging. A very good packaging technology would have very strong visual impact on consumers, and aroused people's purchasing desire. Process method was the design for the packaging process method. On the one hand, this method met the needs of social development and the market, and conformed the state advocated concept of low carbon environmental protection. So, this method could solve many problems. First, the food safety shall be took into consideration, the applied packaging material would not cause pollution, and affected the health of consumers. Secondly, it was the food preservation, a reasonable effective packaging technology could extend the shelf life of food. Third, it was the packaging usage issue. The packaging designed shall be easy to open for consumer. Generally, when consumers choose the food, they would choose the food packaging which were beautiful and simple. Therefore, if enterprise wanted to win in the fierce market competition, the innovation process is a must in the process of food packaging design and neverstopping process method.

\section{E. The Engineering Design Method}

In above information, food packaging design was a comprehensive discipline, which determined its design must be combined with a variety of subjects. Art design was the inevitable result of the continuous development of science, it not only was determined by the single factor of a variety of domains, but also developed with the advance of science technology and the further development of productivity. Human as the main body of the society, in certain social practice, there would be some production rule and the free creation, and the form of aesthetic ability in the natural life activities. Art design had a very close relationship with all of these factors, which was the perfect unification of these factors. When making packaging design, the packaging materials selected must be conformed obey the science and technology guidelines and its use function. So, it needed to evaluate food packaging art design from each aspect and different angles. And engineering was the science relating to the person himself. It mainly studied some mental and physical aspect under particular environment factors, and the mutual relationship between people and environment, and the safety and comfort issue of people's working and life. The human engineering disciplines provided the certain scientific basis for food packaging design, and enabled the design of packaging more scientific and reasonable, comfortable and safe. So for food packaging design, it need to study and analysis the human body engineering for consumers, which involved the production, sale and operation, cost, material, technology, recycling, shape, color and other various factors.

\section{CONCLUSION}

To sum up, in the fierce market competition, food lowcarbon packaging could directly affect the reputation of the enterprise, so each of food companies should pay much attention to its product packaging design and reputation. Food packaging not only must meet the psychological needs of consumers, but also should coordinate with the requirement of low carbon economy, let more consumers feel the scientific progress brings them convenience. Research on food low carbon packaging not only need to have certain systematic point of view, and also need to combine with certain emotional factors. Food packaging design should not just be based on the specific procedures and steps, instead, it shall steam from food packaging design to grasp the influence of various factors, only in such a path of low carbon design could find the right direction. 


\section{REFERENCES}

[1] Dong WANG. Analysis on the low-carbon publication packaging design in low-carbon economy ea[J].Science-Technology \& Publication,2011(8):56-59.

[2] Tian-tao ZHANG, Yuan LIU. Analysis on safety and injury prevention of food packaging[J].Packaging Engineering, 2010,31(16):114-116

[3] Peng ZI. Study on the low-carbon design pattern under the influence of low-carbon economy[J].Packaging Engineering, 2010,31(12):130133

[4] Yan-zai YUAN.Design within design[M].E ZHU, translated. Jinan:Shandong people publishing house, 2009

[5] Zhuan WEI, Guang-jun HUA.Interactive connection of packaging design[J].Packaging Engineering, 2011, 29(10):204

[6] Xiao-tong SHAN. Modern packaging design must pay attention to the affinity[J].Journal of Nanjing Art Institution(Art and design), 2012(3)

[7] Yong-xiang FAN: Safety management situation and countermeasure analysis of food packaging materials at home and abroad[J], Chinese Journal of Food Hygiene, 2009-4(18):342-345. 